\title{
Development and implementation of a tool to assess anatomy knowledge retention
}

\author{
Amaratunga $\mathrm{HA}^{1} *$, Dissabandara $\mathrm{DLO}^{2}$, Adikari $\mathrm{SB}^{1}$, Marambe $\mathrm{K}^{3}$ \\ ${ }^{\prime}$ Department or Anatomy, Faculty of Medicine, University of Peradeniya. \\ ${ }^{2}$ School of Medicine, Griffith University, Australia. \\ ${ }^{3}$ Medical Education Unit Faculty of Medicine, University of Peradeniya. \\ *himanipeiris@yahoo.com
}

Anatomy knowledge is fundamental in practicing medicine. Knowledge acquired during preclinical years may be lost in clinical years. To date, a universally acceptable tool to assess anatomy knowledge retention (AKR) is not available. The objective of this study was to develop and validate AKR tool. Semi-structured interviews were held with clinicians from different disciplines to establish essential anatomy knowledge. Fifty single-bestresponse questions were developed based on this, and discussed with anatomists and clinicians for content validity. Best questions were administered to 30 clinical year students. Point bi-serial index, difficulty-index and KR-20 were calculated. Low point bi-serial was defined as $<0.15$ and response rate $<35 \%$ answering correctly. Questions were graded according to these two parameters into poor, marginal, good and excellent. Marginal questions were edited, poor ones were removed. Developed AKR tool was administered to 15 clinical-year-students, 15 junior doctors and 10 senior doctors. The point bi-serial ranged from (-0.02)0.97.Difficulty index ranged from 29\%$94 \%$. Out of 50 questions, 25 were excellent, 10 good, 11 marginal and 4 poor. Final tool consisted of 46 questions. KR-20 was 0.7 (high reliability). Table shows the marks achieved.

\begin{tabular}{|c|c|c|c|c|c|}
\hline & Limbs\% & Thorax abdomen & Pelvis\% & Neuro\% & Total\% \\
\hline Students & 66.04 & 82.6 & 75.13 & 78.7 & $75.46 \%$ \\
\hline Junior doctor & 59.2 & 73.3 & 72 & 62.5 & $66.75 \%$ \\
\hline Senior doctor & 48.3 & 52.3 & 49.2 & 44 & $48.45 \%$ \\
\hline
\end{tabular}

Students scored highest marks in all regions. Thorax and abdomen region scores were better than that of other regions. Limbs section show lowest marks in students and junior doctors, while the senior doctors had scored lowest in neuroanatomy. It appears that clinical year students have a good anatomy knowledge retention which seems to be continuing as they become doctors but diminishing as they become more experienced. 